\title{
Avaliação multicritério da acessibilidade de pessoas com mobilidade reduzida: um estudo na região central de ltajubá (MG)
}

\author{
Multicriteria evaluation of people with reduced mobility accessibility: a study in \\ downtown Itajubá (MG)
}

Mariza Helena Machado, Josiane Palma Lima

Universidade Federal de Itajubá (Unifei), Itajubá, MG, Brasil

\section{Resumo}

Avaliar a acessibilidade de grupos específicos em um determinado espaço urbano passa por desafios, como verificar as normas técnicas e legislação vigente e considerar a opinião dos indivíduos. Portanto, o objetivo deste trabalho é avaliar a acessibilidade das pessoas com mobilidade reduzida, em relação aos espaços de circulação pública, utilizando um modelo multicritério de avaliação da acessibilidade. 0 objeto de estudo foi o deslocamento pedonal em calçadas, obstáculos, travessias e estacionamentos na região central da cidade de Itajubá, no Estado de Minas Gerais. Verificou-se que os julgamentos dos usuários variam de acordo com o tipo de dificuldade de locomoção e com a disponibilidade de dispositivos e de meios de transportes. 0 estudo fornece subsídios para melhorias de propostas de mobilidade urbana com vistas ao desenvolvimento sustentável, principalmente no que se refere a projetos adequados a um conceito mais abrangente que considere a experiência humana na cidade e viabilize a participação do usuário nos projetos para o coletivo.

\section{Abstract}

Palavras-chave: Acessibilidade. Mobilidade reduzida. Processo Hierárquico Analítico (AHP).

Evaluating the accessibility of specific groups in a determined urban space is challenging, not only when it comes to verifying technical standards and current legislations, but also when considering individual opinions. Therefore, this paper aims to evaluate the accessibility of people with limited mobility in urban public spaces, using an accessibility multi-criteria analysis model. The goal of this study was pedestrian flow in sidewalks, obstacles, crossings and parking spots in downtown Itajubá-MG. It was verified that user's judgment regarding accessibility depends on the different kinds of mobility difficulties, the availability of devices and means of transport. This study provides insights that support better urban mobility proposals for a sustainable development, especially to those projects that aim a social sustainability on a broader concept that embraces human experience in the cities and enables individuals to participate on projects targeted to the general population.

Keywords: Accessibility. Limited mobility. Analytic Hierarchy Process (AHP).

MHM é mestranda em Desenvolvimento, Tecnologias e Sociedade, e-mail: marizamachado@yahoo.com.br JPL é doutora em Engenharia de Transportes, e-mail: jplima@unifei.edu.br 


\section{Introdução}

Quando se planeja um ambiente sustentável, ao mesmo tempo almeja-se o seu desenvolvimento. Aspectos relacionados à mobilidade urbana e à inclusão social remetem-se à sustentabilidade social, que é uma das três dimensões do conceito de "desenvolvimento sustentável", também constituído pela dimensão ambiental e econômica (Reis, 2002; Silva, 2007b).

A sustentabilidade social trata de oportunidades iguais para os seres humanos, dos padrões de atividades em diferentes contextos culturais e sociais em que as pessoas vivem e dos padrões de comportamento relacionados à mobilidade, experiência habitacional, trabalho e relações sociais (Kruse, 1997; Reis \& Lay 2010). Logo, o desenvolvimento sustentável também implica melhoria da qualidade de vida dos seres humanos.

De acordo com a Associação Nacional de Transportes Públicos (ANTP, 2012), em pesquisa realizada nos municípios com mais de 60 mil habitantes em 2011, foram realizadas cerca de 200 milhões de viagens por dia, sendo que $36,8 \%$ desses deslocamentos ocorreram no modo pedonal, deixando clara a importância dos espaços que condicionam o deslocamento a pé. No entanto, 45,6 milhões de brasileiros apresentaram algum tipo de deficiência, ou seja, $23,9 \%$ da população (IBGE, 2010). Destes, 7\% possuíam algum tipo de dificuldade de locomoção ou mobilidade reduzida, excluindo os idosos, as mulheres grávidas, as pessoas obesas e as com dificuldades de locomoção temporárias. Trata-se de uma população expressiva e, em sua maioria, sem a possibilidade de participação nos ambientes de trabalho e de convivência social pela falta de acessibilidade.

Com vistas à sustentabilidade social, as cidades devem ser adaptáveis às percepções específicas dos indivíduos e ser capazes de oferecer condições adequadas de mobilidade para todas as pessoas, indispensável ao exercício da cidadania e ao direito de ir e vir. Pesquisas realizadas sobre cidades e expectativas de mobilidade urbana sustentável apontam vários estudos sobre o tema na literatura atual (CNI, 2012; Kneib, 2012). Contudo, há uma carência de pesquisas que procuram compreender como as pessoas sentem e percebem o espaço e o lugar que habitam, considerando-se que há diferentes maneiras de experimentá-los e interpretá-los.
Avaliar a acessibilidade de grupos específicos, como pessoas com dificuldades de locomoção, em um determinado espaço urbano passa por desafios, entre eles, como considerar a opinião e o julgamento desses indivíduos. Os métodos, que, em geral, baseiam-se em normas técnicas e em legislação, podem ser adaptados com o intuito de buscar uma abordagem mais ampla para o estudo e a compreensão da acessibilidade, bem como a percepção do espaço e do ambiente em que esses grupos vivem.

Portanto, este trabalho tem por objetivo avaliar a acessibilidade e a percepção pedonal das pessoas com mobilidade reduzida, em relação aos espaços de circulação pública, utilizando um modelo multicritério de avaliação da acessibilidade. 0 objeto de estudo foi o deslocamento a pé ou em cadeira de rodas, utilizando-se as calçadas, travessias e estacionamentos, já que são locais que legitimam o caminhar. Utiliza-se a abordagem multicriterial da avaliação da acessibilidade, uma vez que os critérios da norma técnica foram agrupados e ponderados por meio do Processo Hierárquico Analítico (do inglês Analytic Hierarchy Process - AHP).

\section{Acessibilidade para pessoas com mobilidade reduzida}

O Decreto n. 5.296, de 2 de dezembro de 2004 (Brasil, 2004), conceitua pessoa com mobilidade reduzida aquela que, não se enquadrando no conceito de pessoa com deficiência, tenha dificuldade de movimentar-se permanente ou temporariamente, sendo prejudicada e reduzida sua mobilidade, flexibilidade, coordenação motora e percepção. Complementando, o Decreto define como "ajuda técnica", ou "assistiva", os produtos, instrumentos, equipamentos ou tecnologia adaptados ou projetados para melhorar a funcionalidade da pessoa com deficiência ou mobilidade reduzida, favorecendo a autonomia pessoal, ou seja, no caso da deficiência física, cadeira de rodas, órteses ou próteses, bengalas, muletas e andadores (Brasil, 2004).

Assim, nem sempre quem possui mobilidade reduzida se enquadra na categoria de pessoas com deficiência, como crianças, grávidas ou idosos. A dificuldade do movimento, que reduz a mobilidade, é inerente à condição humana e sempre estará presente em todos os estágios do desenvolvimento humano.

Segundo o Ministério das Cidades (Brasil, 2006), a mobilidade do pedestre pode ser afetada por vários fatores, como o trânsito, os obstáculos arquitetônicos, 
sua renda, sua idade, seu sexo, sua capacidade de compreender mensagens, sua condição física e sua capacidade para utilizar os transportes. Sendo assim, torna-se primordial tratar os deslocamentos a pé não apenas como exercício de direitos, mas a partir do conceito de mobilidade, acrescido da preocupação com a sustentabilidade. Desde então, um novo conceito vem sendo abordado: a mobilidade urbana sustentável. Tratase de uma proposta de planejamento de mobilidade que não privilegia os veículos, e sim as pessoas, com suas peculiaridades e fragilidades, sendo o ponto principal a ser considerado em uma política de desenvolvimento urbano. Deslocar-se e ter acesso promove a inclusão social, a equiparação de oportunidades e o exercício de direitos das pessoas, principalmente das pessoas com deficiência física e mobilidade reduzida.

Para Lévy (2001, p. 1), mobilidade urbana é a

[...] relação social ligada à mudança de lugar, isto é, como um conjunto de modalidades pelas quais os membros de uma sociedade tratam a possibilidade de eles próprios ou outros ocuparem sucessivamente vários lugares".

A mobilidade urbana se liga, portanto, ao conjunto de possibilidades de um indivíduo ou de um grupo ocupar vários lugares sucessivamente. Essa mobilidade independe dos meios utilizados, mas depende da presença ou não de obstáculos impeditivos para a ocupação.

Por sua vez, a mobilidade implica acessibilidade. Falar de acessibilidade, em termos gerais, é garantir a possibilidade do acesso, da aproximação, da utilização (Vasconcellos, 2012). A acessibilidade éa “ [....] possibilidade e condição de alcance, percepção e entendimento para utilização com segurança e autonomia de edificações, espaço, mobiliário, equipamento urbano e elementos" (ABNT, 2004). A Lei Federal n. 12.587, de 3 de janeiro de 2012 (Brasil, 2012), define como: “[...] facilidade disponibilizada às pessoas que possibilite a todos autonomia nos deslocamentos desejados".

Duarte \& Cohen (2004) comentam que a acessibilidade ao espaço construído não deve ser compreendida como um conjunto de medidas que favoreçam apenas às pessoas com deficiência, o que poderia até aumentar a exclusão socioespacial e a segregação desses grupos, mas sim medidas técnico-sociais destinadas a acolher todos os usuários em potencial.

Para Santos et al. (2005), a acessibilidade tornou-se o ditame principal nas relações da sociedade para com os seus integrantes com deficiência, abrangendo um amplo conjunto de aspectos, como emprego, saúde, educação, reabilitação etc., e também o espaço urbano e edificado, que deve receber a pessoa com deficiência livre de barreiras arquitetônicas e urbanas. Os autores comentam ainda que, por mais que se tenha ciência desse panorama, por mais que haja regulamentos que determinem a eliminação de barreiras, sua aplicação ainda se verifica muito restrita, e o que se vê é a falta de acessibilidade no ambiente em geral.

Portanto, acessibilidade, em termos gerais, é garantir a possibilidade do acesso, da aproximação, da socialização e da utilização de qualquer ambiente. Indica a condição favorável de um determinado pedestre dentro de suas capacidades individuais de se movimentar, locomover e atingir o destino planejado, porém é decorrente da oferta do ambiente.

\section{Modelo multicritério para avaliação da acessibilidade}

A acessibilidade pedonal é determinada por um grande número de fatores que dependem das características do local a ser avaliado, que pode ser uma edificação ou mesmo um percurso frequentemente utilizado por um grupo de usuários. No entanto, avaliar a acessibilidade de grupos específicos em um determinado espaço urbano passa por desafios, como adaptar métodos objetivos com o intuito de buscar uma abordagem que considere a opinião desses usuários. Nesse sentido, a abordagem multicriterial da avaliação da acessibilidade considera critérios que medem as condições reais e incorporam os julgamentos da pessoa com mobilidade reduzida.

A utilização do método de Análise de Decisão Multicritério (do inglês Multicriteria Decision Analysis - MCDA) (Voogd, 1983; Carver, 1991; Malczewski, 1999) requer uma articulação entre os objetivos de quem decide e a identificação dos critérios necessários para que o objetivo seja alcançado. 0 critério é medido de acordo com a sua função em relação ao objetivo. 0 método de análise multicritério possibilita empregar julgamentos de valor e aparece como uma opção para que as diversidades se agreguem, ao reconhecer que a subjetividade é inerente ao problema (Costa, 2006).

Entre os vários métodos existentes (Saaty, 1980; Bana e Costa \& Vansnick, 1994; Zietsman et al., 2003; Lima et al., 2009), optou-se por trabalhar com o AHP proposto por Saaty (1980), pois é uma alternativa para que os diversos pontos de vista possam ser 
transformados em julgamentos de valor e tratados cientificamente (Barbosa, 2012). É uma ferramenta de fácil entendimento e aplicação, não necessitando de programas específicos de computador ou de modelos matemáticos complexos para seu uso (Lima etal., 2009).

Para aplicação da metodologia MCDA, algumas etapas devem ser seguidas, como a fase de estruturação do modelo, por meio da definição do problema, da definição de critérios e da estruturação hierárquica, e a fase de avaliação, em que aspectos críticos do processo de decisão são considerados, como a avaliação de pesos para os critérios, a normalização dos critérios e a combinação de critérios.

A Figura 1 descreve sumariamente as etapas do método utilizado.

\section{Avaliação da acessibilidade na região central de ltajubá (MG)}

0 presente estudo foi realizado na cidade de Itajubá, no Estado de Minas Gerais, localizada a $445 \mathrm{~km}$ de distância da capital, Belo Horizonte. Possui uma população de 90.658 habitantes, distribuídos demograficamente em uma densidade de $307,49 \mathrm{hab} / \mathrm{km}^{2}$. Não diferente da porcentagem do Brasil, Itajubá (MG) possui 6,2\% de pessoas com algum tipo de dificuldade motora, ou seja, 5.621 pessoas, excluindo-se aqui os idosos, grávidas, obesos e as com dificuldades temporárias (IBGE, 2010).

Seleção dos participantes da pesquisa e do percurso

Tanto a legislação quanto a norma técnica são voltadas para a acessibilidade de todas as pessoas com deficiência, englobando as com deficiência auditiva, visual, intelectual e física. Entretanto, as necessidades são diferentes e específicas; assim, nem sempre quem possui uma deficiência física possui mobilidade reduzida. Ademais, mulheres grávidas e idosos são pessoas com mobilidade reduzida e não apresentam deficiência. Neste trabalho, os participantes da pesquisa são as pessoas com mobilidade reduzida, usuárias de cadeira de rodas, bengalas e muletas e que foram selecionadas por meio de duas etapas.

A primeira etapa contou com uma pesquisa no cadastro de uma organização não governamental do município que trabalha com a inclusão social de pessoas com deficiência, sendo a única fonte municipal com cadastro de adultos com mobilidade reduzida.

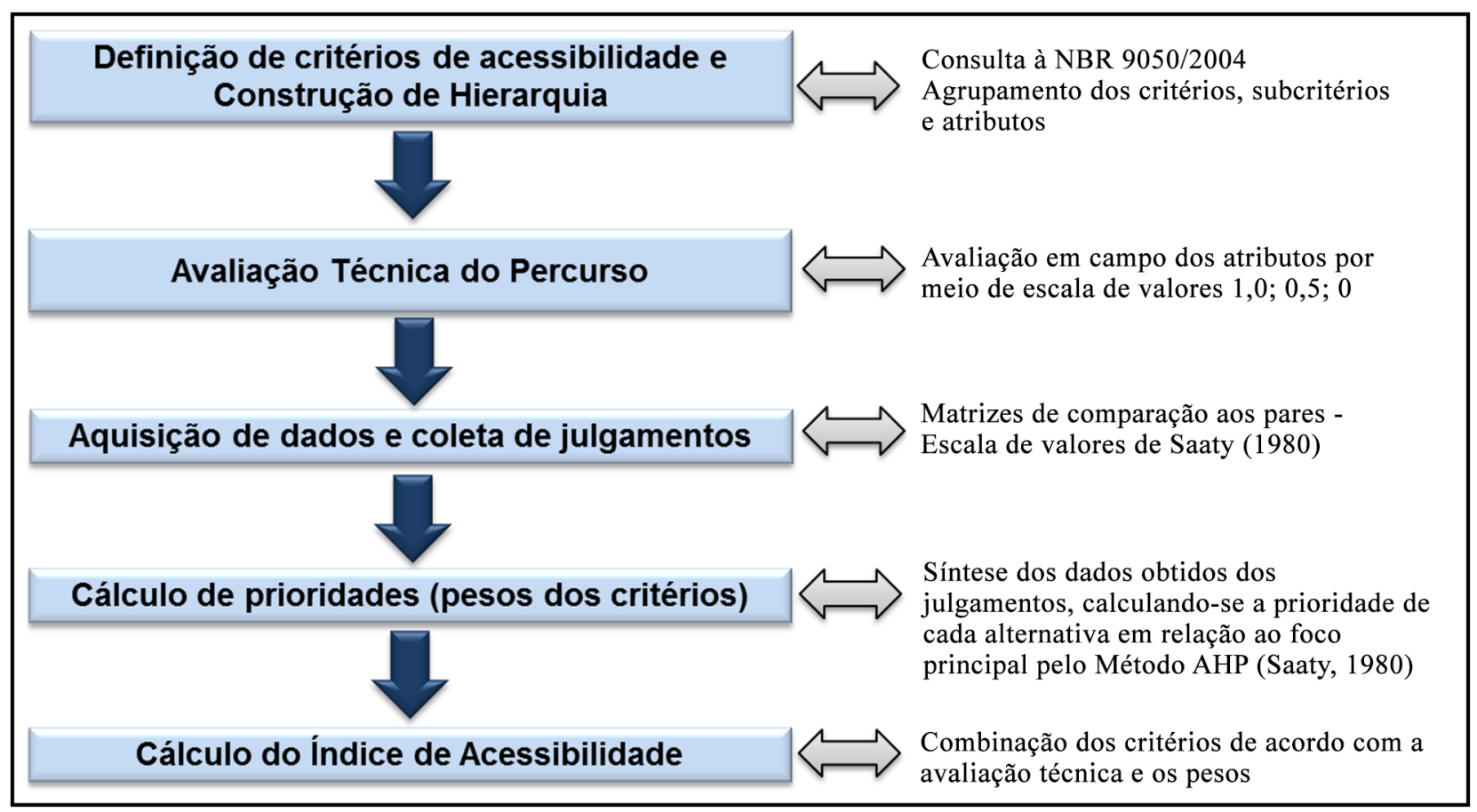

Figura 1 - Método multicritério de avaliação da acessibilidade

Fonte: Elaborado pelo autor. 
Foram selecionadas previamente 20 pessoas com mobilidade reduzida, de acordo com os critérios: usuárias de cadeira de rodas, bengala ou muletas, que não necessitam de ajuda de terceiros para seus deslocamentos e que se deslocam com frequência pela cidade como pedestres.

A segunda etapa contou com um questionário que possibilitou, além da escolha dos participantes da pesquisa, a coleta dos locais mais frequentados, as atividades realizadas nesses locais e a frequência de realização desses percursos. Assim, a partir dessas informações, selecionou-se sete pessoas com mobilidade reduzida que tinham em comum a circulação em pontos específicos da cidade e, apoiando-se nessa informação, determinou-se o percurso a ser estudado.

0 percurso situa-se na região central da cidade, com um total de $600 \mathrm{~m}$. É um local com alta fluência de pessoas, variados comércios, bares, restaurantes, lojas e outros ofícios, tanto públicos quanto privados. Comporta, em um dos trechos, uma área exclusiva para pedestres, denominada simplesmente "Calçadão", sendo local de lazer para os munícipes, ponto de festividades municipais, feiras e shows. 0 mapa da Figura 2 apresenta o percurso e a divisão dos trechos, os principais locais (ruas e praças) e o ponto de início e fim escolhido para coleta de dados.

Para facilitar a coleta de dados e avaliar os trechos mais críticos, os $600 \mathrm{~m}$ de percurso, referenciados pelo número do lote, foram divididos em seis trechos com $100 \mathrm{~m}$ de comprimento cada, sendo denominados neste estudo de Trecho A, B, C, D, E e F.

Foram pesquisados na literatura alguns trabalhos sobre a avaliação da acessibilidade para o perfil dos usuários em questão. Assim, esta pesquisa teve ainda como referência os trabalhos de Duarte \& Cohen (2006),

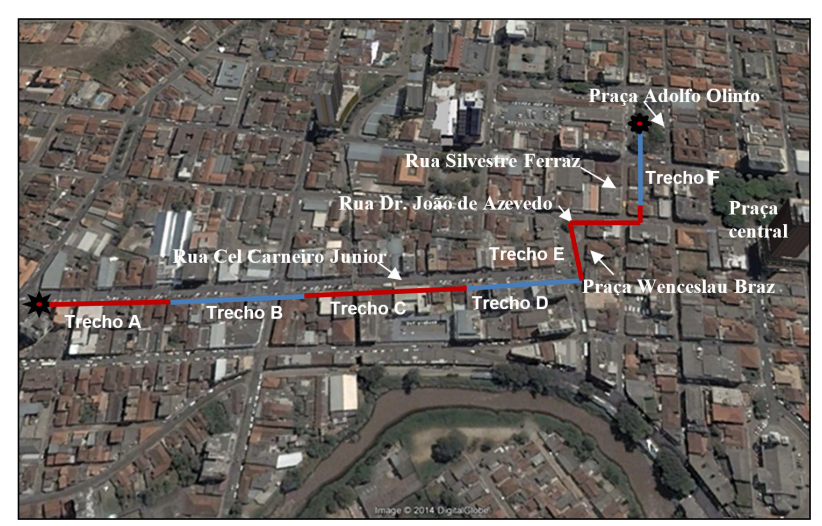

Figura 2 - Localização de percurso. Região central de Itajubá (MG) Fonte: Elaborado pelo autor com base na Imagem do Google Earth. que desenvolveram uma metodologia de avaliação da acessibilidade aos espaços de ensino fundamental por meio de planilha tipo checklist, e o trabalho de Silva (2007a), cujo escopo foi o desenvolvimento de um índice de acessibilidade para pessoas com mobilidade reduzida. Observou-se que ambos os trabalhos foram fundamentados na NBR 9050 (ABNT, 2004).

Assim, os fatores levantados foram então agrupados em quatro grupos de critérios a serem avaliados, sendo eles: a geometria das calçadas, os obstáculos físicos presentes no percurso, as condições das travessias e a oferta de vagas especiais para estacionamento.

\section{Determinação dos critérios de análise}

Uma das etapas mais importantes deste trabalho foi a definição dos critérios para avaliação da acessibilidade. Para esse fim, foram observadas, primeiramente, a legislação pertinente e a norma técnica: Decreto n. 5.296 (Brasil, 2004) e NBR 9050 (ABNT, 2004). Realizou-se uma seleção dos parâmetros técnicos que deveriam ser respeitados nos projetos de acessibilidade e que tinham uma relação mais próxima com as necessidades das pessoas com mobilidade reduzida, não se considerando os critérios para outros tipos de deficiências, como as visuais, auditivas ou intelectuais, aqui inclusos o piso tátil, semáforo sonoro, sinalização ambiental etc.

\section{Análise técnica dos atributos do percurso}

As condições de cada atributo da geometria das calçadas, obstáculos, travessias e estacionamentos foram avaliadas e quantificadas. Utilizou-se uma escala subjetiva para verificar se as condições dos itens selecionados atendiam ou não à legislação e à normativa técnica. Cada atributo foi avaliado separadamente, recebendo uma pontuação que poderia ser $0,0,5$ ou 1,0 ponto. 0 valor 1,0 significaria que o atributo era integralmente atendido em toda a extensão do trecho de acordo com a norma técnica, ou seja, uma situação ideal. 0 valor 0,5 indicaria que o trecho atendia parcialmente ( $2 / 3$ do comprimento total) à norma, apresentando alguma irregularidade em um ponto específico, mas não impedia o acesso. Uma situação de total inadequação, que impedisse e dificultasse o acesso, receberia o valor 0 . A Tabela 1 
apresenta a planilha utilizada para análise técnica em campo e os valores encontrados durante a coleta de dados.

Durante o levantamento em campo das condições do percurso, foram feitas várias observações e registros fotográficos dos problemas encontrados. Constatou-se que em vários trechos o piso possuía muitos danos e deformidades, com revestimentos danificados, escorregadios ou inexistentes (Figura 3a). A superfície não era estável nem regular, provocando solavancos

Tabela 1 - Critérios e análise técnica nos seis trechos do percurso

(continua)

\section{Critérios de avaliação}

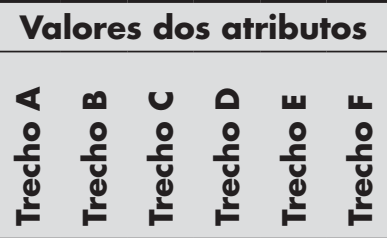

\section{A. Geometria das calcadas}

\section{A.1 Características do Piso}

A.1.1 Superfície regular, firme, estável, contínua e antiderrapante sob quaisquer condições.

A.1.2 Que não provoca trepidaç̃̃o em dispositivos com rodas.

A.1.3 Padronagem na superfície do piso que possa causar sensação de insegurança (estampas que, pelo contraste de cores, possam causar a impressão de tridimensionalidade).

A.1.4 Pisos de praças regulares, firmes, antiderrapantes, contínuos, sem trepidação.

$\begin{array}{cccccc}0 & 0 & 0 & 0 & 0,5 & 0 \\ 0 & 0 & 0 & 0 & 0,5 & 0 \\ 1,0 & 1,0 & 1,0 & 1,0 & 0 & 1,0\end{array}$

\section{A.2 Largura da calcada}

A.2.1 Faixa livre de circulação com largura mínima de 1,20 m.

A.2.2 Faixas livres desobstruídas, sem barreiras para o livre trânsito de pedestres (equipamentos não urbanos).

\section{A.3 Equipamentos urbanos}

A.3.1 Equipamentos urbanos (caixa de correio, placas sinalizadoras, vegetação, lixeiras, telefones públicos) localizados fora do espaço de passagem (faixa livre) dos pedestres.

A.3.2 Obstáculos aéreos localizados a uma altura superior a 2,10 m em relação ao piso da calçada (marquises, placas sinalizadoras, toldos). $\quad \begin{array}{lllll}1,0 & 1,0 & 0,5 & 1,0 & 1,0\end{array} \quad 1,0$

\section{A.4 Inclinação}

A.4.1 Inclinação transversal do piso é de no máximo 3\%.

A.4.2 As calçadas e vias exclusivas de pedestres não apresentam indinação longitudinal superior a 8,33\% (1:12).

\section{B. Obstáculos}

\section{B.1 Desniveis}

B.1.1 0 piso apresenta-se completamente nivelado, sem ressaltos.

B.1.2 Desniveis acima de 5,00 mm até 15,00 mm estão tratados em forma de rampa, com inclinação máxima de 50\% (1:2).

B.1.3 Desniveis superiores a 15,00 mm são considerados como degraus, apresentando-se devidamente sinalizados.

B.1.4 Grelhas fora do fluxo principal e, se no fluxo, com vãos verticais de até $15,00 \mathrm{~mm}$.

B.1.5 Tampas de caixas de inspeção e de visita niveladas com o piso.

$\begin{array}{llllll}1,0 & 0 & 0 & 1,0 & 1,0 & 0,5\end{array}$

$\begin{array}{llllll}0,5 & 0 & 0,5 & 0 & 1,0 & 1,0\end{array}$

$\begin{array}{llllll}1,0 & 1,0 & 1,0 & 1,0 & 1,0 & 0,5\end{array}$

\section{B.2 Obras na calcada}

B.2.1 Presença de obras na calçada e devidamente isoladas.

B.2.2 Está assegurada uma faixa liver $(1,20 \mathrm{~m})$ para a circulaç̃o de pedestres.

B.2.3 Na ausência de faixa livre, há um desvio pelo leito carroçável de no mínimo 1,00 m de largura, com rampas de inclinação máxima de 10\%.

Fonte: Elaborado pelo autor.

$\begin{array}{cccccc}0 & 0 & 0 & 0 & 0,5 & 0 \\ 0 & 0 & 0 & 0 & 1,0 & 1,0 \\ 0 & 0 & 0 & 0 & 1,0 & 1,0 \\ 0,5 & 1,0 & 0,5 & 1,0 & 0 & 0 \\ 0 & 0 & 0 & 0 & 1,0 & 0\end{array}$

$\begin{array}{llllll}1,0 & 1,0 & 1,0 & 1,0 & 1,0 & 1,0\end{array}$

$\begin{array}{lllllll}1,0 & 1,0 & 1,0 & 1,0 & 1,0 & 1,0\end{array}$

$\begin{array}{llllll}1,0 & 1,0 & 1,0 & 1,0 & 1,0 & 1,0\end{array}$ 
Tabela 1 - Critérios e análise técnica nos seis trechos do percurso

(conclus̃̃o)

\begin{tabular}{|c|c|c|c|c|c|c|}
\hline \multirow[b]{2}{*}{ Critérios de avaliação } & \multicolumn{6}{|c|}{ Valores dos atributos } \\
\hline & 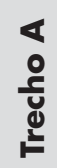 & 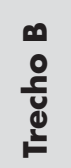 & 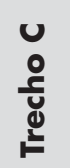 & 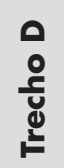 & 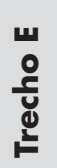 & 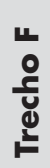 \\
\hline \multicolumn{7}{|l|}{ B.3 Acesso de veículos aos imóveis (garagem) } \\
\hline $\begin{array}{l}\text { B.3.1 A acomodação de acesso de véículos é feita exclusivamente dentro do imóvel, de forma a não criar degraus ou desniveis abruptos } \\
\text { na calçada. }\end{array}$ & 1,0 & 1,0 & 1,0 & 0 & 1,0 & 1,0 \\
\hline \multicolumn{7}{|l|}{ C. Travessias } \\
\hline \multicolumn{7}{|l|}{ C.1 Rebaixamento de calçadas para travessia de pedestres } \\
\hline $\begin{array}{l}\text { C.1.I Nas calcadas, em locais com faixa destinada à travessia de pedestres em via pública, há rebaixamento nivelado do meio-fio ou } \\
\text { rampa sobre a calçada. }\end{array}$ & 0 & 0 & 1,0 & 0,5 & 0,5 & 0 \\
\hline C.1.2 Há uma faixa de circulaçã̃o plana, livre e contínua na calçada em frente à rampa com no mínimo 80,00cm de largura. & 0 & 0 & 1,0 & 0 & 0 & 0 \\
\hline C.1.3 A rampa possui largura mínima de $1,20 \mathrm{~m}$. & 1,0 & 1,0 & 1,0 & 1,0 & 1,0 & 0,5 \\
\hline C.1.4 A inclinação deve ser constante e não superior a 8,33\% (1:12). & 1,0 & 1,0 & 0 & 1,0 & 1,0 & 0 \\
\hline C.1.5 Os rebaixamentos das calçadas localizados em lados opostos da via devem estar alinhados entre si. & 1,0 & 0,5 & 0,5 & 1,0 & 1,0 & 1,0 \\
\hline \multicolumn{7}{|l|}{ C.2 Faixas para travessia de pedestres } \\
\hline $\begin{array}{l}\text { C.2.1 As faixas devem ser aplicadas nas seç̃oes de via em que houver demanda de travessia, iunto a semáforos, focos de pedestres, no } \\
\text { prolongamento das calcadas e passeios. }\end{array}$ & 1,0 & 1,0 & 1,0 & 1,0 & 1,0 & 1,0 \\
\hline C.2.2 Existem semáforos para carros. & 1,0 & 1,0 & 1,0 & 1,0 & 0 & 0 \\
\hline C.2.3 0 tempo destinado à travessia de pedestres é dimensionado adequadamente. & 1,0 & 1,0 & 1,0 & 1,0 & 1,0 & 0,5 \\
\hline \multicolumn{7}{|l|}{ D. Estacionamento } \\
\hline D.1.1 Há pelo menos 2\% do total de vagas reservados para véiculos que transportem pessoa com deficiência. & 1,0 & 1,0 & 1,0 & 1,0 & 1,0 & 1,0 \\
\hline D.1.2 Sinalização espećfica e visivel indicando o local da vaga (tanto nas vagas horizontais à calçada quanto nas verticais). & 1,0 & 1,0 & 1,0 & 1,0 & 1,0 & 1,0 \\
\hline D.1.3 Quando afastadas da faixa de travessia de pedestres, a vaga está associada ou próxima à rampa de acesso à calçada. & 1,0 & 1,0 & 0,5 & 1,0 & 1,0 & 0 \\
\hline
\end{tabular}

Fonte: Elaborado pelo autor.

em dispositivos de rodas. Havia grelhas no Trecho A, C, E e F, com vão de 35 mm (Figura 3b), e quase todas as tampas e caixas de inspeção e de visita não se encontravam niveladas com o piso (Figura 3c). As travessias possuíam, de modo geral, faixas bem destacadas no chão e rampas (Figura 3d). Entretanto, nos trechos B, C, e E, o que chama atenção é que algumas rampas apresentavam-se sem faixa livre de acesso, com largura mínima abaixo de 1,20 m, invadindo toda a calçada, e sem nivelamento com o piso, sendo que o desnível chegava a $32 \mathrm{~mm}$. 0 Trecho D possuía inclinações horizontais na calçada devido à entrada de garagem, gerando também degraus. No trecho E, que se insere na área denominada "Calçadão", o piso era revestido de pedra portuguesa e apresentava desníveis no assentamento, com mudança abrupta de piso em alguns locais sem razão aparente e sem nenhuma sinalização, o que, além de provocar trepidação em cadeira de rodas, gerava também instabilidade (Figuras 3e e 3f). 0 Trecho F tinha uma rampa de acesso à calçada com inclinação excessiva, demandando a necessidade da ajuda de terceiros na transposição.

Observou-se ainda no Trecho $\mathrm{C}$ que a caixa de correio, apesar de estar posicionada adequadamente na calçada, tornou-se um obstáculo aéreo, pois a largura da passagem livre era inferior a 1,20 m, exigida por norma (Figura 3g). Constatou-se também obstáculos provocados por terceiros, como a presença de lixo acumulado na calçada (Figura $3 \mathrm{~h}$ ), interferindo na largura mínima para passagem de um cadeirante, muito frequente nos dias de coleta de lixo, serviço prestado pela prefeitura com maior frequência aos sábados e no final do horário comercial. Apesar de 


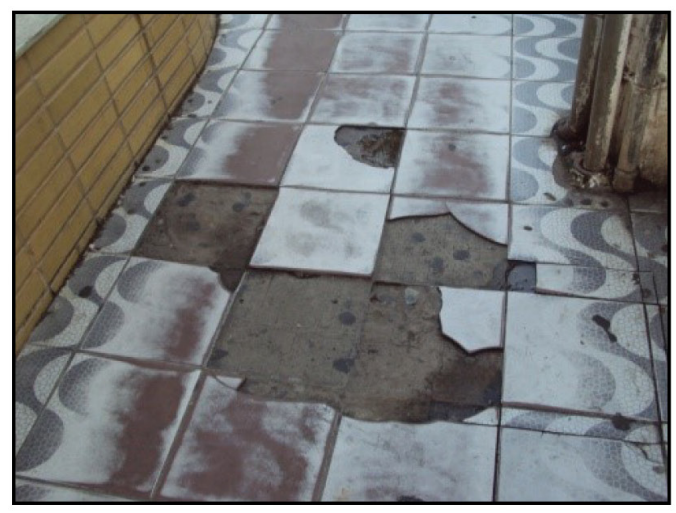

(a) Buracos e avarias

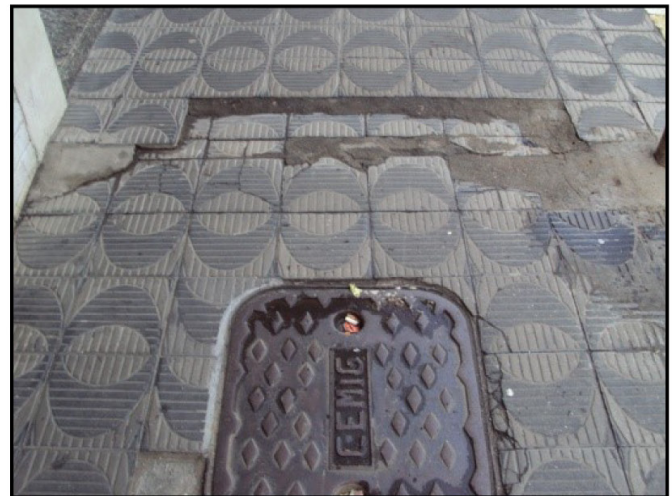

(c) Desníveis no piso

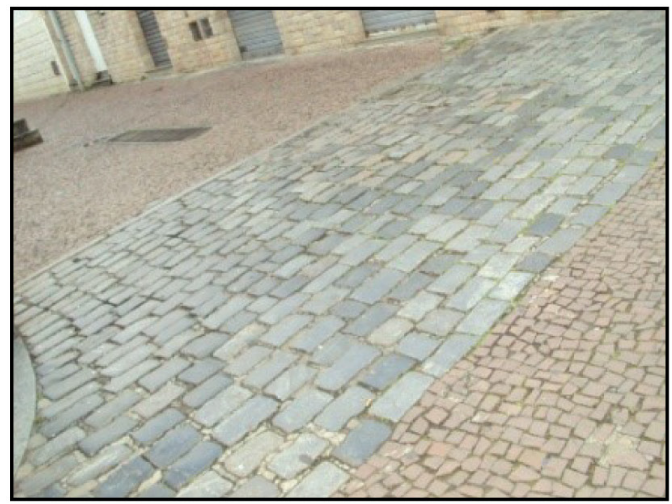

(e) Mudança de piso

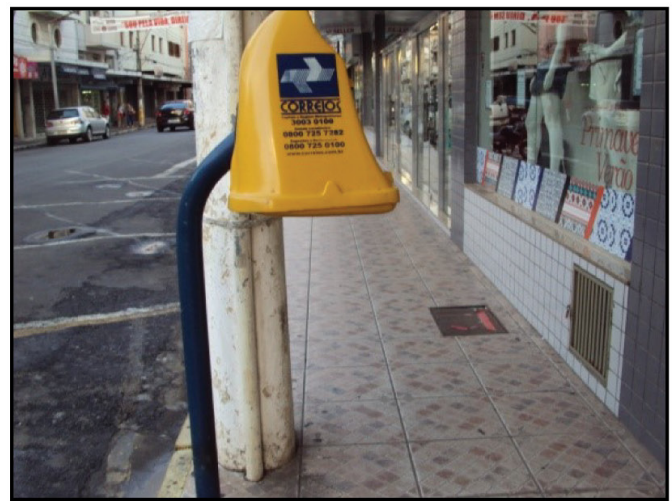

(g) Obstáculo aéreo

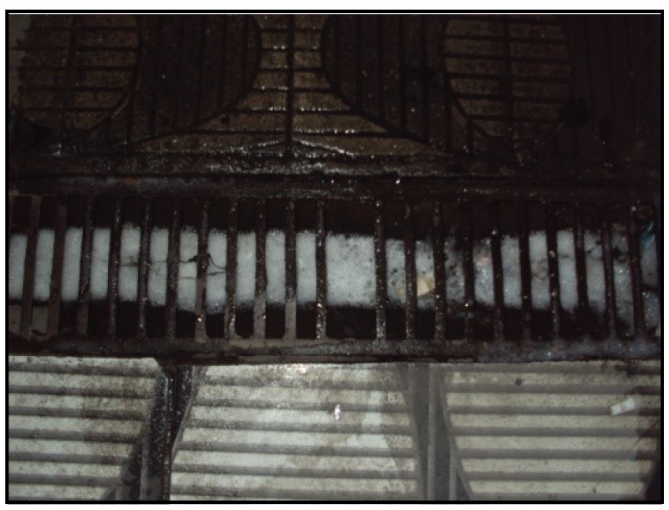

(b) Grelha com vão largo

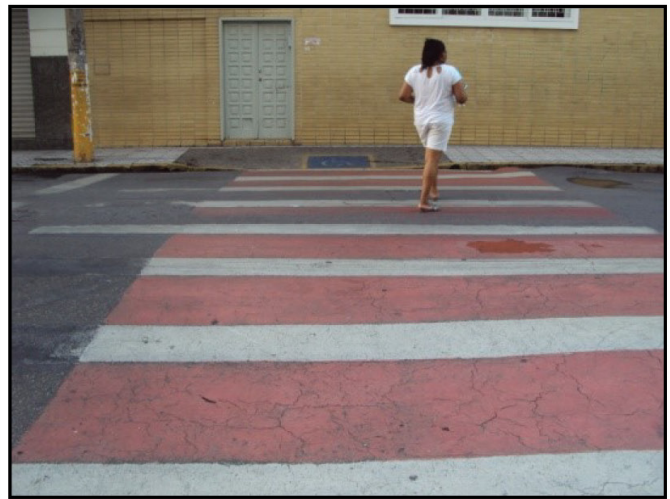

(d) Travessia sinalizada

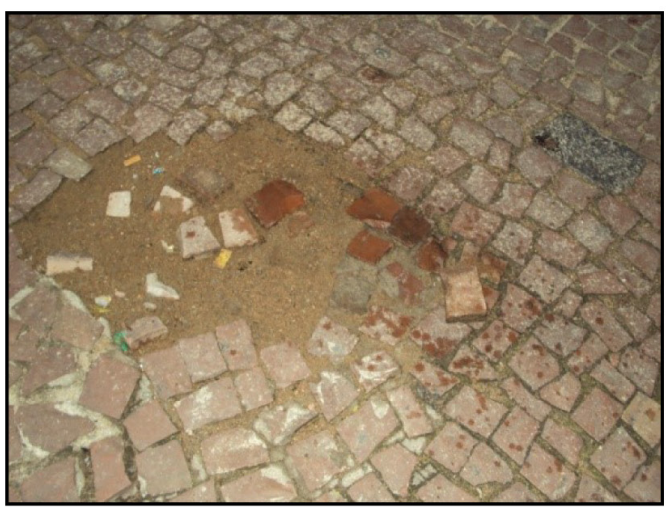

(f) Irregularidades no piso

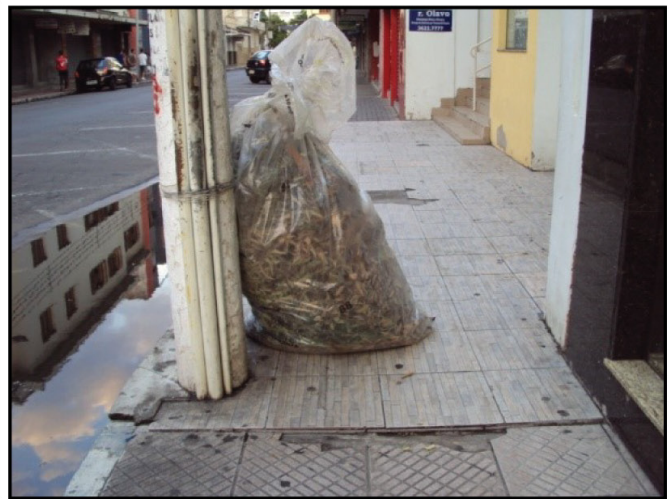

(h) Presença de lixo

Figura 3 - Observações e levantamento de campo Fonte: Elaborado pelo autor. 
alguns trechos não possuírem vagas de estacionamento reservadas para pessoas com deficiência, no percurso total $(600 \mathrm{~m})$ as vagas obedeciam à reserva de $2 \%$ da área de estacionamento. Contudo, não estavam associadas próximas às rampas de acesso às calçadas.

A Figura 3 ilustra algum dos aspectos observados e encontrados em campo

Julgamento dos critérios sob o ponto de vista da pessoa com mobilidade reduzida

Depois de estruturado o conjunto de critérios que faria parte do processo de avaliação, realizou-se a avaliação técnica em campo e foi necessário definir a importância relativa de cada critério e grupos de critérios em relação ao objetivo almejado, ou seja, acessibilidade por pessoas com mobilidade reduzida. Com esse objetivo, foram realizados os agrupamentos dos critérios, conforme Tabela 1, e a construção hierárquica da estrutura de avaliação, apresentada na Figura 4.

A definição dos pesos dos critérios foi realizada por meio do AHP. Por intermédio dessa técnica, pesos e prioridades eram derivados a partir de um conjunto de julgamentos subjetivos realizados por avaliadores envolvidos no processo.

Foi utilizada a escala de comparação par a par de critérios proposta por Saaty (1980), composta por nove níveis numéricos, para expressar e normalizar os julgamentos efetuados. 0 critério era medido dentro de uma escala de extremamente menos importante a extremamente mais importante, como ilustrado na Figura 5.

Da psicologia quantitativa, que trabalha precisamente com a expressão de preferências de pessoas ao longo de escalas, Saaty descobriu que a melhor escala para um julgamento de valor era aquela que terminava em 7+ ou -2, evitando-se, assim, a ancoragem, ou seja, quando as notas ficavam ancoradas em subintervalos

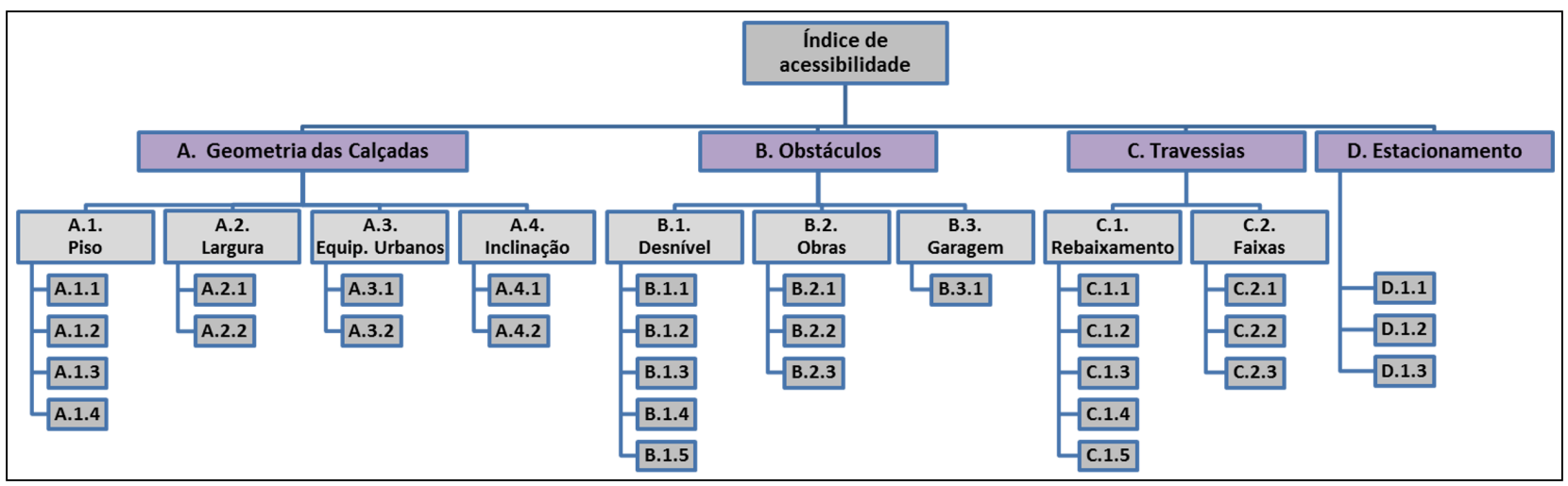

Figura 4 - Estrutura hierárquica para avaliação do índice de acessibilidade Fonte: Adaptado de Lima et al. (2009).

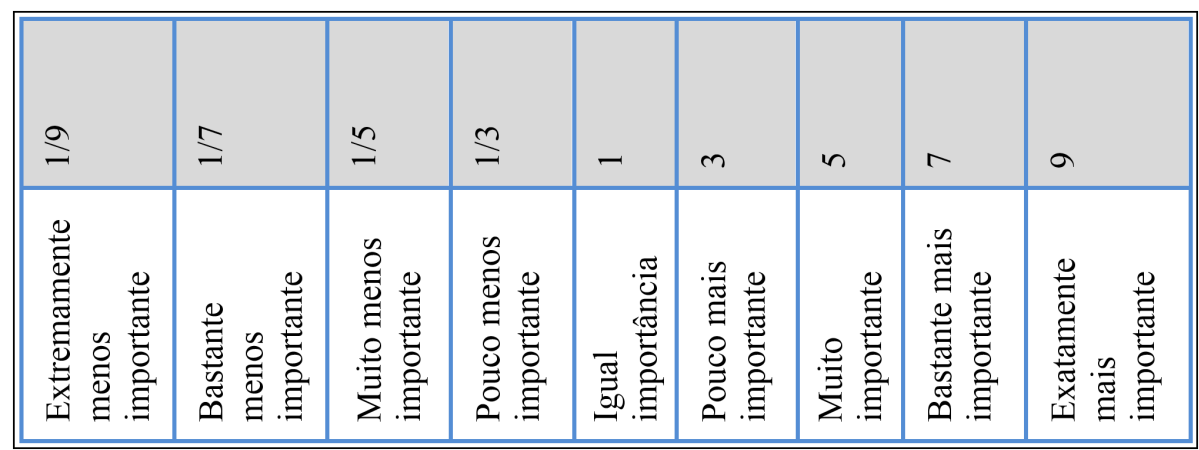

Figura 5 - Escala de comparaç̃ão de critérios (Saaty, 1980) Fonte: Adaptado de Lima et al. (2009). 
da escala, eram usadas escalas de 1 até 7 ou 9 (Gomes, 2004).

A hierarquia objetivava a análise das interações de seus elementos. As comparações par a par entre os elementos da estrutura retratavam o raciocínio humano, expressando-o matematicamente. Essas comparações forneceram as importâncias relativas, ou os pesos, de cada atributo. Assim, uma estrutura bem construída seria estabelecida em um bom modelo matemático. Os pesos refletiam os julgamentos e determinavam quais critérios tinham maior prioridade na tomada de decisão.

A comparação entre os critérios foi realizada a partir do primeiro nível e por meio de uma matriz quadrada $n \times n$, elaborada neste trabalho em planilha eletrônica, conforme o exemplo do primeiro nível, apresentado na Figura 6. Os critérios foram distribuídos, na mesma ordem, nas linhas e nas colunas, e apenas a metade superior direita era avaliada (Lima, 2007).

As matrizes foram organizadas em forma de questionário para aplicação aos usuários do percurso, isto é, pessoas com mobilidade reduzida. Como alguns usuários/avaliadores não dominavam ou não possuíam computador, foi necessária a aplicação presencial das matrizes.

Dessa forma, o julgamento foi realizado considerando questões norteadoras, sendo que, no primeiro nível da estrutura (Figura 2), procedia-se a escolha dos pares do critério que se julgava mais importante em relação ao objetivo proposto, neste caso, a acessibilidade ao destino. Assim, os sete avaliadores fizeram seus julgamentos, atribuindo importância e valores aos critérios. Os pesos representavam os julgamentos dos usuários com mobilidade reduzida, atribuídos aos critérios e aos respectivos subcritérios. Assim, depois de ter determinado o peso de cada critério, o método permitia calcular o Grau de Consistência (CR - Consistency Ratio) dos julgamentos efetuados (para mais detalhes e aplicação sobre o método, ver Lima, 2007). 0 resultado da avaliação no primeiro nível é apresentado na Tabela 2.

Sob o ponto de vista das pessoas com mobilidade reduzida, o grupo geometria das calçadas apresentou um grau de importância maior que o dos outros grupos de critérios (obstáculos, travessias e estacionamentos), sendo apontado como o fator mais importante para a acessibilidade, com grau de importância (peso) igual a 0,572 .

Os obstáculos vieram na segunda posição, com 0,199 , seguidos das travessias, com peso de 0,139 , e a disponibilidade de vagas de estacionamento, com o menor grau de importância, com peso de 0,09. Verificou-se, durante a aplicação da pesquisa, que os julgamentos dos usuários variaram de acordo com o modo de se locomover, ou seja, com o tipo de deficiência e com o uso de dispositivos auxiliares de locomoção, como a cadeira de rodas, as muletas e as bengalas, e também de acordo com as condições sociais. No processo de julgamento dos critérios de acessibilidade, muitos elementos atuaram para que a pessoa pudesse se deslocar, ou seja, suas competências de deslocamento. Sua destreza, velocidade no caminhar, força física, postura e outras deficiências correlacionadas eram fatores a serem considerados nos julgamentos. Quanto menor o grau de mobilidade, maiores eram as necessidades e as dificuldades enfrentadas.

0 usuário de muletas axilar (Avaliador 6 - Tabela 2) atribuiu uma importância um pouco maior para as travessias e obstáculos, quando comparado aos outros avaliadores, pois possuía menos velocidade no caminhar e postura diferenciada, já que disse caminhar com olhar focado no chão, e não no horizonte. Já o usuário de muletas tipo canadense ou de punho (Avaliador 4), com destreza e velocidade maiores, considerou em seu julgamento os obstáculos presentes em um dado percurso menos importantes do que os

\begin{tabular}{|l|l|l|l|l|}
\hline ACESSIBILIDADE & GEOMETRIAS DAS CALÇADAS & TRAVESSIA & ESTACIONAMENTO & OBSTÁCULOS \\
\hline GEOMETRIA CALÇADAS & 1 & & & \\
\hline TRAVESSIA & & 1 & & \\
\hline ESTACIONAMENTO & & & 1 & 1 \\
\hline OBSTÁCULOS & & & & \\
\hline
\end{tabular}

Figura 6 - Matriz de comparação par a par Fonte: Adaptado de Lima et al. (2009). 
Tabela 2 - Grau de importância atribuído por cada avaliador aos critérios do nível 1

\begin{tabular}{lcccccccc}
\hline \multicolumn{1}{c}{ Avaliadores } & Aval. 1 & Aval. 2 & Aval. 3 & Aval. 4 & Aval. 5 & Aval. 6 & Aval. 7 & Média \\
\hline 1. Calcada & 0,216 & 0,632 & 0,637 & 0,676 & 0,665 & 0,505 & 0,676 & $\mathbf{0 , 5 7 2}$ \\
2. Obstáculo & 0,271 & 0,202 & 0,195 & 0,137 & 0,158 & 0,268 & 0,158 & $\mathbf{0 , 1 9 9}$ \\
3. Travessia & 0,102 & 0,128 & 0,131 & 0,153 & 0,141 & 0,189 & 0,130 & $\mathbf{0 , 1 3 9}$ \\
4. Estacionamento & 0,411 & 0,038 & 0,036 & 0,035 & 0,036 & 0,038 & 0,036 & $\mathbf{0 , 0 9 0}$ \\
\hline
\end{tabular}

Fonte: Elaborado pelo autor.

outros avaliadores, pois os contornava ou transpunha com uma certa facilidade, mantendo uma postura corporal e um campo de visão mais amplo. 0 tipo de instrumento auxiliar também influenciou nos julgamentos, pois uma cadeira de rodas motorizada transpõe obstáculos independentemente da força física de quem a maneja, o que não acontece com os usuários de cadeira de rodas manual; já muletas axilares fornecem menos mobilidade para os usuários do que as muletas canadenses.

0 atributo estacionamento apresentou também uma variabilidade significativa no julgamento do Avaliador 1, se comparado aos demais julgamentos. Constatou-se que isso se deve ao fato da necessidade ou não da utilização dessas vagas para estacionar veículo próprio ou da frequência de utilização delas para desembarque, ou seja, pelo meio de transporte utilizado. Portanto, possuir um carro modificou o julgamento da pessoa. Constatou-se ainda que, quanto piores as condições sociais e econômicas, maior a necessidade do deslocamento a pé e do uso de transporte público, já que, em sua maioria, não possuíam carro e moravam nos bairros periféricos.

A Tabela 3 apresenta os pesos que representam os julgamentos dos usuários com mobilidade reduzida, atribuídos aos critérios e aos respectivos subcritérios.

Dentro do critério geometria das calçadas, as condições dos pisos apresentaram o maior peso $(0,462)$. A superfície irregular, os buracos, as mudanças de padrão e os pisos escorregadios foram apontados como a causa de acidentes sérios e, quase sempre, de mudanças obrigatórias no trajeto. A inclinação da calçada, tanto transversal como longitudinalmente, foi o segundo subcritério com maior peso $(0,338)$. Inclinação excessiva requer maior força física e contribui para o desequilíbrio e quedas, independentemente de ser usuário de cadeira de rodas, bengala ou muletas. Os mobiliários urbanos dispostos na calçada, aéreos
Tabela 3 - Pesos dos critérios e subcritérios de avaliação da acessibilidade

\begin{tabular}{lclc}
\hline \multicolumn{1}{c}{ Critérios } & Pesos & Subcritérios & Pesos \\
\hline \multirow{4}{*}{ Geometria das calcadas } & & Piso & 0,462 \\
& & Largura & 0,097 \\
& & Equipamentos urbanos & 0,103 \\
& & Inclinação & 0,338 \\
Obstáculos & & Desnivel & 0,558 \\
& 0,199 & Obras & 0,061 \\
Travessias & & Garagem & 0,381 \\
& & Rebaixamento & 0,788 \\
Estacionamento & 0,139 & Faixa pedestre & 0,212 \\
\hline
\end{tabular}

Fonte: Elaborado pelo autor.

ou no chão, foram considerados o terceiro mais importante para o acesso $(0,103)$. Por fim, a largura teve o menor peso $(0,097)$, quando comparada aos outros subcritérios. Entretanto, foi apontada como um fator que poderia impedir totalmente o acesso em dado trecho, ocasionando também a mudança no trajeto.

Já no grupo obstáculos, o maior peso foi atribuído ao subcritério desnível $(0,558)$, que poderia provocar acidentes por não estar devidamente sinalizado ou tratado como rampa. Desníveis elevados foram considerados degraus e, muitas vezes, foram intransponíveis para alguns usuários. Por exemplo, as grelhas de escoamento propiciavam a entrada das rodas da cadeira ou permitiam que a ponta de muletas e de bengalas entrasse pela abertura, se a largura fosse superior à permitida. Já as caixas de visita e de inspeção, se não estivessem niveladas com o piso, funcionavam como degraus ou desníveis. Ainda no grupo obstáculos, o acesso a garagens $(0,381)$ teve o segundo maior peso, 
já que as elevações ou depressões abruptas e sem sinalização podiam impedir ou dificultar o acesso. As obras na calçada apresentaram o menor peso $(0,061)$, pois foram consideradas esporádicas e, se sinalizadas ou com desvios adequados, provocavam poucas dificuldades de acesso.

No grupo travessias, o maior peso foi atribuído ao rebaixamento das calçadas nas faixas de travessias $(0,788)$. Havia a necessidade de rampas niveladas com o piso, com largura certa, alinhada com sua oposta, sem degrau e com inclinação adequada, bem como faixa livre para o pedestre onde se posicionavam as rampas. A diminuição da largura da faixa livre ou a sua ausência também foram apontadas como razões de falhas na acessibilidade. Quando a rampa invadia toda a calçada, provocava inclinações para o usuário que, assim, não iria utilizar da rampa. Interessante também foi a constatação pelos sujeitos de que rampas muito inclinadas eram consideradas obstáculos, e não uma contribuição para a acessibilidade. Ainda no grupo travessias, com peso inferior, o subcritério faixa de pedestre ficou em segundo lugar $(0,221)$, sendo que a falta de semáforos para pedestres prejudicava a acessibilidade, mas não impedia o deslocamento.

Por fim, a disponibilidade de vagas de estacionamento ficou com peso igual a 0,090 em relação aos outros grupos de critérios, sendo considerado o grupo de menor importância para a acessibilidade, pois sua necessidade dependia do tipo de transporte que o sujeito utilizava, ou seja, dependia de cada usuário. Constatou-se também que o critério estacionamento foi julgado de forma diferente pelos sujeitos. 0 fato de possuir carro próprio ou de ser transportado por veículo particular teve influência nos julgamentos e no grau de importância atribuído a esse critério, pois esse perfil de sujeito atribuiu uma importância maior para a oferta das vagas de estacionamento e para as rampas de acesso às calçadas. Geralmente, tentavam estacionar seus veículos o mais próximo possível de seus objetivos, evitavam locais menos acessíveis e percorriam pequenos trajetos como pedestres, comparado aos que não possuíam veículo, o que justificou suas escolhas.

Os pesos podem variar em razão de certas especificidades. Usuários de cadeira de rodas motorizadas possuem mobilidade e acessibilidade maiores do que os cadeirantes de rodas manuais, já que estes usam maior força física para transpor certos obstáculos. No entanto, pessoas com muletas ou bengalas podem ter acesso mais fácil em espaços com menor largura, se comparados com os usuários de cadeira de rodas, já que seus instrumentos auxiliares ocupam menor espaço e são mais flexíveis para o deslocamento. Da mesma forma, quem usa muletas ou bengalas transpõe degraus com mais facilidade do que usuários de cadeira de rodas. A escolha do instrumento auxiliar para a locomoção ou tecnologia assistiva depende não só da disponibilidade financeira do indivíduo, mas também do tipo de mobilidade que possui. Cadeiras motorizadas não estão ao alcance de todos e nem sempre um usuário de muletas terá maior mobilidade em uma cadeira.

\section{Índice de acessibilidade}

0 índice de acessibilidade é um valor que incorpora os julgamentos das pessoas com mobilidade reduzida, expressos por meio dos pesos de cada critério, os valores normalizados dos atributos, coletados por intermédio da análise técnica de cada trecho, e o posterior agrupamento dos critérios.

O índice foi determinado pela agregação dos escores obtidos para os vários grupos de critérios (Escore C $_{\mathrm{c}}$ em avaliação, para cada trecho determinado. Cada Escore $_{\mathrm{c}}$ resultou da média ponderada dos escores de cada subcritério (Escore ${ }_{\mathrm{sc}}$ ), os quais, por sua vez, eram obtidos pela agregação dos escores normalizados dos vários atributos (Escore ${ }_{\mathrm{a}}$ ). Os vários subcritérios (critérios do nível 2) podiam ser complementares ou equivalentes. Por esse motivo, fez-se a agregação em grupos de critérios similares. Assim, o índice de acessibilidade passou a ser avaliado por grupos de critérios, conforme a Equação 1, na qual Escore e w ${ }_{c}$ são, respectivamente, o escore normalizado e ponderado e o peso atribuído a cada grupo de critérios.

$$
I A=\frac{\sum_{c}\left(\text { Score }_{c} \times w_{c}\right)}{\sum_{c} w_{c}}
$$

Os valores dos índices de acessibilidade em cada trecho do percurso são apresentados na Tabela 4.

Pelos índices obtidos, observou-se que os trechos não são homogêneos. Havia trechos com índices de acessibilidade melhores que outros, sendo que a média revelou um índice de 0,654, em uma escala que variou de 0 (pior condição de acessibilidade) a 1,0 (melhor condição de acessibilidade). 
Tabela 4 - Valores do índice de acessibilidade

\begin{tabular}{rccccccc}
\hline Método & Trecho A & Trecho B & Trecho C & Trecho D & Trecho E & Trecho F & Média \\
\hline Com os julgamentos & 0,709 & 0,668 & 0,663 & 0,545 & 0,725 & 0,618 & 0,654 \\
Sem os julgamentos & 0,822 & 0,771 & 0,746 & 0,713 & 0,843 & 0,641 & 0,756 \\
\hline
\end{tabular}

Fonte: Elaborado pelo autor.

0 trecho com o menor índice foi o Trecho D, com 0,545 , e no qual foram apontados problemas diversos. Era o único trecho que apresentava piso escorregadio e desníveis com inclinação excessiva em entrada de garagem, critérios esses com pesos altos, o que fez com que esse trecho fosse o pior em termos de acessibilidade.

Já o Trecho E foi o que apresentou melhor índice de acessibilidade $(0,725)$ e compreendia quase todo $o$ "Calçadão". Mesmo apresentando algumas avarias, piso que provocava trepidações e grelhas de escoamento com vãos de largura superior ao permitido, foram critérios com pesos menores no julgamento dos usuários, que não impediam o acesso ao destino e que podem ter sido responsáveis pela obtenção do melhor índice.

0 método proposto também permitiu calcular o índice de acessibilidade considerando ou não os julgamentos dos usuários, ou seja, das pessoas com mobilidade reduzida. Utilizando-se da mesma técnica, contudo sem o julgamento das pessoas com mobilidade reduzida, o valor do índice médio foi maior, com 0,756. Quem apresentou também o melhor índice foi o trecho E $(0,843)$. Entretanto, o trecho de pior índice difere do julgamento dos participantes, sendo o Trecho F o detentor $(0,641)$, o que só comprovou a importância da avaliação sob a perspectiva do usuário.

Assim, verificou-se que, em todos os trechos, o índice aumentou quando não eram considerados os julgamentos, ou seja, levando-se em conta que todos os critérios tivessem o mesmo peso. Dessa forma, verificou-se que, quando eram considerados os pesos que refletiam os julgamentos, o índice representou de forma mais real as condições de acessibilidade.

Portanto, para aplicar o modelo de acessibilidade, é necessário que sejam conhecidos: os critérios de decisão, os pesos a aplicar a cada critério e aos grupos de critérios e os valores dos atributos.

\section{Conclusões}

Este trabalho avaliou a acessibilidade por meio de uma metodologia que incorporou os principais fatores que interferiam na acessibilidade e o julgamento das pessoas com mobilidade reduzida.

A coleta de dados possibilitou o contato direto com os indivíduos e a percepção das necessidades e particularidades desse segmento. Os resultados dos julgamentos de critérios para a acessibilidade, sob o ponto de vista das pessoas com mobilidade reduzida, mostraram que o grau de importância do grupo geometria das calçadas foi maior que os outros grupos de critérios, com $57 \%$ do peso total, indicando que os aspectos relacionados ao piso, largura e inclinação foram os que mais condicionaram o acesso do indivíduo. Notou-se que, em ambientes acessíveis, todos tinham as mesmas oportunidades.

Durante o levantamento de dados, os julgamentos dos usuários variaram de acordo com o tipo de dificuldade de se locomover e com a disponibilidade e tipo de instrumentos assistivos utilizados para a locomoção. As técnicas de avaliação para melhorias da mobilidade e de acessibilidade deveriam, portanto, considerar as individualidades humanas e as suas capacidades ou competências motoras, abandonando o conceito de homem-padrão ou médio, pois, para serem eficientes, os espaços urbanos deveriam ser projetados de acordo com a gama de medidas do corpo humano (Palnero \& Zelnik, 2002).

A idade, a dificuldade de mobilidade, se era permanente ou temporária, adquirida ou congênita, não foram avaliadas nesta pesquisa, porém, com certeza, influenciaram na mobilidade do indivíduo, o que, por si só, já é um importante objeto de análise.

Sob o ponto de vista técnico, o estudo de caso na região central da cidade de Itajubá (MG) possibilitou avaliar de forma efetiva o percurso. A divisão do percurso estudado em vários segmentos permitiu pontuar áreas críticas, o que facilita a priorização 
nos planejamentos urbanos e auxilia os decisores na alocação de recursos disponíveis, atendendo às reais necessidades da população.

O uso do Método AHP ofereceu um procedimento construído por meio da percepção e do julgamento dos avaliadores e determinou a relação de importância de todos os critérios de acessibilidade, possibilitando a aplicação de índices de acessibilidade e a identificação e informação sobre as reais necessidades da parcela estudada. Os resultados encontrados se inseriram nas necessidades e nas realidades dos pesquisados, contemplando na avaliação um público que, geralmente, não é consultado na confecção das normas, regulamentos e no planejamento urbano.

O método é flexível e permite incorporar novos critérios, ou, ainda, outros tipos de ambiente e de deficiência, como a visual, auditiva e intelectual.

Finalmente, este estudo poderá contribuir em melhorias na formulação de políticas públicas inclusivas de mobilidade urbana com vistas ao desenvolvimento sustentável, principalmente no que se refere à sustentabilidade social. A gestão da infraestrutura urbana precisa ser adequada a um conceito mais abrangente, que considere a experiência humana e as suas vivências na cidade e viabilize a participação do usuário nos projetos para o coletivo.

\section{Referências}

Associação Brasileira de Normas Técnicas - ABNT. (2004). NBR 9050: acessibilidade à edificações, mobiliário, espaços e equipamentos urbanos. Rio de Janeiro.

Associação Nacional de Transportes Públicos - ANTP. (2012). Sistema de Informação da Mobilidade Urbana. São Paulo. Relatório Geral de Mobilidade Urbana, 2011.

Bana e Costa, C. A., \& Vansnick, J. C. (1994). MACBETH - An interactive path towards the construction of cardinal value functions. International Transactions in Operational Research, 1(4), 489-500. http://dx.doi. org/10.1016/0969-6016(94)90010-8

Barbosa, L. F. S. (2012). Formulação de um Modelo Multicritério para a Avaliação de Acessibilidade na concepção de prédios (Dissertação de mestrado). Sistemas de Gestão, Universidade Federal Fluminense, Rio de Janeiro.

Brasil. (2004, 3 de dezembro). Decreto no 5.296, de 2 de dezembro de 2004. Regulamenta as Leis No 10.048 e 10.098. Brasília: Diário Oficial da União, seção 1, p. 5.
Brasil. Ministério das Cidades. (2006). Programa Brasil Acessível - Programa Brasileiro de Acessibilidade Urbana, cadernos 1 a 6. Brasília. Recuperado em 6 de novembro de 2014, de www.cidades.gov.br

Brasil. (2012, 4 de janeiro). Lei Federal no 12.587, de 3 de janeiro de 2012. Institui as diretrizes da Política de Mobilidade Urbana e dá outras providencias. Brasília: Diário Oficial da União, seção 1, p. 1.

Carver, S. J. (1991). Integrating multi-criteria evaluation with Geographical Information Systems. International Journal of Geographic Information Systems, 5(3), 321-339.

Confederação Nacional da Indústria - CNI. (2012). Cidades: mobilidade, habitação e escala um chamado à ação. Brasília. $98 \mathrm{p}$.

Costa, H. G. (2006). Auxílio multicritério à decisão: método AHP. Rio de Janeiro: ABEPRO, LATEC-UFF.

Duarte, C. R. S., \& Cohen, R. (2004). Acessibilidade aos espaços de ensino e pesquisa: desenho universal na UFRJ - Possível ou utópico? In Anais do NUTAU: Demandas Sociais, Inovações Tecnológicas e a Cidade. São Paulo: USP.

Duarte, C. R. S., \& Cohen, R. (2006). Proposta de metodologia de avaliação da acessibilidade aos espaços de ensino fundamental. In Anais do NUTAU: Demandas Sociais, Inovações Tecnológicas e a Cidade. São Paulo: USP.

Gomes, L. F. A. M. (2004). Tomada de decisões em cenários complexos: introdução aos métodos discretos do apoio multicritério à decisão. São Paulo: Pioneira Thomson Learning.

Instituto Brasileiro de Geografia e Estatística - IBGE. (2010). Censo Demográfico 2010: características gerais da população, religião e pessoas com deficiência. Rio de Janeiro. Recuperado em 6 de novembro de 2014, de www. ibge.gov.br

Kneib, E. C. (2012). Mobilidade urbana e qualidade de vida: do panorama geral ao caso de Goiânia. Revista UFG, 13(12), 71-78.

Kruse, L. (1997). Evolving the concept of sustainability. In Proceedings from Conference of the International Association for People-environment Studies (Vol. 1, p. 10-12). Stockholm: Department of Architecture and Town planning, Royal Institute of Technology.

Lévy, J. (2001). Os novos espaços da mobilidade. Geographia, 3(6). Recuperado em 5 de agosto de 2015, de http://www. 
uff.br/geographia/ojs/index.php/geographia/article/ view $/ 62 / 60$

Lima, J. P. (2007). Modelo de decisão para a priorização de vias candidatas às atividades de manutenção e reabilitação de pavimentos (Tese de doutorado). Engenharia dos Transportes, Escola de Engenharia, Universidade de São Paulo, São Carlos.

Lima, J. P., Ramos, R. A. R., \& Fernandes, J. L., Jr. (2009). Uma abordagem multicritério para a priorização de vias pavimentadas. Revista dos Transportes, 17(1), 27-38.

Malczewski, J. (1999). GIS and multicriteria decision analysis. New York: John Wiley \& Sons.

Palnero, J., \& Zelnik, M. (2002). Dimensionamento humano para espaços interiores: um livro de consulta e referência para projetos. Barcelona: Gustavo Gili.

Reis, A. T. L., \& Lay, M. C. D. (2010). 0 projeto da habitação de interesse social e a sustentabilidade social. Ambiente Construído, 10(3), 99-119. http://dx.doi.org/10.1590/ S1678-86212010000300007

Reis, A. (2002). Aparência, qualidade e habitação sustentável. In Anais do IX Encontro Nacional de Tecnologia do Ambiente Construído (p. 1105-1112). Foz do Iguaçu: ANTAC.
Saaty, T. L. (1980). The analytic hierarchy process. New York: McGraw Hill.

Santos, A., Santos, L. K. S., \& Ribas, V. G. (2005). Acessibilidade de habitações de interesse social ao cadeirante: um estudo de caso. Ambiente Construído, 5(1), 55-75.

Silva, J. L. (2007a). Índice de acessibilidade: IA. In Anais da LXIV Semana Oficial da Engenharia, da Arquitetura e da Agronomia. Rio de Janeiro.

Silva, V. G. (2007b). Indicadores de sustentabilidade de edifícios: estado da arte e desafios para desenvolvimento no Brasil. Ambiente Construído, 7(1), 47-66.

Vasconcellos, E. A. (2012). Mobilidade urbana e cidadania. Rio de Janeiro: SENAC Nacional.

Voogd, H. (1983). Multicriteria evaluation for urban and regional planning. London: Pion.

Zietsman, J., Rilet, L. R., \& Kim, S. (2003). Sustainable transportation performance measures for developing communities. Texas: Texas Transportation Institute. Report 167128.

Recebido: Fev. 8, 2015

Aprovado: Mar. 17, 2015 